\section{Sustainability science: a review, an analysis and some empirical lessons}

\author{
JOACHIM H. SPANGENBERG ${ }^{1,2 *}$ \\ ${ }^{1}$ Sustainable Europe Research Institute Germany eV, Vorsterstrasse 97, 51103 Cologne, Germany, and ${ }^{2}$ UFZ \\ Helmholtz Centre for Environment Research, Halle, Germany
}

Date submitted: 27 May 2010; Date accepted: 11 April 2011;

First published online: 14 June 2011
THEMATIC SECTION

Interdisciplinary Progress

in Environmental

Science \& Management

\section{SUMMARY}

Sustainability science has developed from a new research field into a vibrant discipline in its own right, with scientific conferences, journals and scientific societies dedicated to its pursuit. Characterized more by its research purpose than by a common set of methods or objects, sustainability science can be subdivided into the more traditional disciplinary-based science for sustainability and the transdisciplinary science of sustainability. Whereas the former consists of more descriptive, analytical and basic science, the latter is characterized by reflexivity and applicability; on a meta level, the emergence of the latter can be understood as a new step in the evolution of science. This review provides an overview of the state of sustainability science, identifying action orientation, integrated assessments and interdisciplinarity as overall characteristics. The review also focuses on methodological issues, highlighting differences in project organization and management, and the ways in which stakeholder participation can be organized in interdisciplinary and transdisciplinary research projects. Sustainability science is recognized as essential for progress towards sustainability, and as an opportunity to bring science closer to the people, requiring significant changes in the way science is organized and conducted.

Keymords: extended peer community, post normal science, research management, science policy interface, sustainability science, transdisciplinarity

\section{INTRODUCTION}

Sustainable development is considered a key issue facing the 21st century (Komiyama \& Takeuchi 2006), an overarching policy paradigm (see European Commission 2010a), even a new world view for the 21st century (Eckersley 2006). What is needed to deal with this challenge is critical advances in basic knowledge, in humankind's social and technological capacity to use it, and in the political will to turn that knowledge

${ }^{*}$ Correspondence: Dr Joachim Spangenberg e-mail: Joachim. Spangenberg@gmx.de and know-how into action (Weinstein 2010). Research for sustainability, seeking real-world solutions to sustainability problems, can contribute to all three aspects, however it requires substantial understanding of the subject matter at stake. Research would otherwise risk answering questions that might not make any sense in the sustainability context (Meppem \& Bourke 1999).

\section{Sustainable development}

Sustainable development is a global development concept giving overriding priority to the satisfaction of human needs, in particular of the global poor, while respecting environmental limits (WCED [World Commission on Environment and Development] 1987). The International Union for the Conservation of Nature (IUCN) et al. (1991) defined it as the capacity to maintain a certain process or state for improving the quality of human life, while living within the carrying capacity of supporting ecosystems. Thus sustainability is not a positive analytical concept, but a normative ethically justified utopia, describing a state of economy, society and environment considered optimal (Morus 1517).

In systems science terms, sustainable development requires synchronizing a metasystem and its nested, complex and evolving subsystems nature, economy and society (Bossel 1998) over the long term and including distant interferences (WCED 1987). Sustainable development must deal with non-linear effects and delayed responses driving the system beyond cause-effect logic, with feedback loops and extensive temporal-spatial heterogeneity (Allen 2001). It focuses on the interlinkages among dimensions (Weaver \& Rotmans 2006) and ensures that each of these systems is sustainable in itself, being able to reproduce and deal with the dynamics of the system environment (Bossel 1996), while not impinging on the other systems' ability to do the same. Only then can development of the metasystem be sustained. Systems science is a promising approach to developing a coherent description of sustainability, but its application is still in its infancy and fraught with problems (Weinstein 2011).

Sustainable development strategies are essentially attempts to answer one vital question: 'At multiple scales and over succeeding generations, how can the earth, its ecosystems, and its people interact towards the mutual benefit and sustenance of all?' (Weinstein 2011). They have to address multiple levels and scales, and must be aware of the fact that what 
is sustainable at one level might contribute to unsustainability at a higher level (Martens 2006).

Most countries of the world now have sustainable development strategies, but with different priorities and conceptual approaches (Spangenberg 2008). This owes not only to the different socioeconomic and biogeophysical situations, but also to conflicts of interest between competing powers in each society, as sustainable development affects their partisan interests. Struggling for social hegemony, interest groups try to define sustainability in their own particular way. The seminal paper of Kates et al. (2001) emphasized that a key challenge is the resolution of competing interests; there is rarely a solution maximizing gains for all, thus satisfying all stakeholders. Trade-offs are unavoidable and must be compensated for by complementary measures; there is no single simple solution and waiting for what economists call win-win-win situations to emerge is senseless. Sustainability exists at all levels, from the national (see for example Moran et al. 2008) to the local (Hartmuth et al. 2008).

\section{Sustainability science}

It is not long since there were calls for a science that was adequate to address sustainability predicated on recognition of the fundamental link between science and economy, while remaining free of political bias in an attempt 'to be responsive to the needs and values in society while preserving the life support systems of planet Earth' (Kates et al. 2001, p. 641; see also Komiyama \& Takeuchi 2006). What was fiercely discussed was whether sustainability science was just a subtopic of other sciences, a cross-cutting question or a new discipline in its own right (ICSU [International Council for Science] 2002; Clark \& Dickson 2003). The answer now seems clear: although an 'umbrella term' (Kastenhofer et al. 2011), sustainability science has emerged as a 'not yet mature' (Ostrom et al. 2007), but distinctive, vibrant and maturing field of research, defined by problems rather than by the disciplines it employs (Clark 2007; Kajikawa et al. 2007). Disciplines have been defined as 'stable systemic communities within which members contribute their experience into a particular world view' (Bruce et al. 2004, p. 458). Sustainability science is emerging as such a discipline, with sustainability the core of its distinctive worldview (Kauffman 2009). Thousands of papers are published annually (Kajikawa et al. 2007), lectures held and master courses developed in Europe, Asia and the USA, and Harvard has established a fellowship for sustainability science (see URL http://sustainabilityscience.org/content.html? contentid= 2894). Academic journals include Sustainability Science (see URL http://www.springer.com/environment/environmental+management/journal/11625) and Sustainability: Science, Practice, E Policy (see URL http://sspp.proquest. com/about/about.html), while conferences, web fora and scientific societies have embraced the sustainable development and sustainability science and a special section has been established in the journal Proceedings of the National Academy of Sciences of the United States of America (see URL http://www.pnas.org/site/misc/sustainability.shtml) with numbers of papers submitted increasing (Kauffman 2009). Sustainability science is emerging as a dynamic and evolving transdisciplinary effort addressing symbiosis between human activity and the environment (Rapport 2007), providing visions and scenarios indicating transition pathways towards global sustainability (Komiyama \& Takeuchi 2006) while elucidating relevant decisions and agents (Raskin 2008). Today sustainability science is usually understood as research providing the necessary insights to make the normative concept of sustainability operational, and the means to plan and implement adequate steps towards this end. Given this broad description, sustainability science can and must provide room for different disciplines, philosophies of science and methodologies, as long as they share the insight that a transition of societal structures, institutions and regulation modes towards sustainability is necessary and urgent. This pre-scientific pre-analytical vision, world view or metaphysics calls for more than incremental or sectoral change. It shapes the problem definition and, consequently, the kind of research questions asked and the approaches chosen (Daly et al. 1990). The importance of a sound problem definition cannot be exaggerated, as it frames the direction of research and the policy discourse: the problem definition is both a normative and analytical effort, taking into account the concept of sustainable development, the values at stake, the roots of the problem and the decision-making space available (Ascher 2007).

This broad definition already allows identification of three characteristics of sustainability science, which seem to emerge as a defining consensus in the sustainability science research community (Kauffman 2009):

(1) It may be basic or applied research, but it must be purpose-bound, as opposed to the 'value free' stance of natural sciences: as sustainability is a normative concept, sustainability science must be aimed at action. Methodological pluralism is a necessary characteristic of sustainability science as a whole, although not necessarily of each research project.

(2) Sustainability science provides integrated analyses and assessments. Integrated assessment is a reflective and iterative participatory process that links knowledge (science) and action (policy) regarding complex science and technology issues. It is an interdisciplinary process, combining, interpreting and communicating knowledge from diverse scientific disciplines and non-scientific sources in such a way that the whole cause-effect net of a problem can be evaluated from a synoptic perspective, providing added value compared to single disciplinary assessments and offering useful information to decision makers.

(3) Sustainability science must be either interdisciplinary or at least 'interdisciplinarity-ready', conducted in a way which allows the integration of its results in an interdisciplinary context, bringing disciplines together to achieve greater consistency in approaches between them. 
I distinguish here between multidisciplinarity (several disciplines working parallel, with limited interaction, on a shared object of interest), interdisciplinarity (researchers from different disciplines working together in a way that their results can be integrated) and 'transdisciplinarity'.

Transdisciplinarity is a demanding form of knowledge integration and it is dependent on reflectivity. It requires a non-idealized perception of the objects of research, a reflection on the specific limitations of the disciplinary construction of reality. Only then can researchers possibly deal with these constructions as problems that can be approached from a diversity of different angles, each one legitimate in its own right and capable of contributing partial knowledge of the object, but none able to define the problem as such from a disciplinary perspective. This is also the condition for the other defining element of transdisciplinarity, namely the involvement of extended peer communities, not only in dissemination of research results, but also in the research process itself. Extended peer communities means the involvement of diverse disciplines as in interdisciplinarity, plus tacit and experience-based knowledge, in particular knowledge regarding the relevance of issues (Funtowicz \& Ravetz 1993), as in a knowledge society knowledge is dispersed and cannot be monopolized by a single group, in this case the scientific system and community (Funtowicz et al. 1999). Thus in transdisciplinarity, the sources of intelligence are extended to include non-scientific knowledge (see below), the research question is defined together, and the quality of the work is checked by both groups, as those affected are the experts for relevance, while scientists are the experts for rigour (Mittelstrass 1992; Jerneck et al. 2011).

Sustainability science research is now conducted in a multitude of countries, and increasingly involves international collaboration, mostly between neighbouring countries (Yarime et al. 2010). Fifteen research clusters have emerged, with the main themes being urban planning, rural sociology, energy, health, soil, wildlife, agriculture, fisheries, ecological economics and forestry. Key terms found across many themes include education, biotechnology, medical, lifestock, climate change, welfare and livelihoods (Kajikawa et al. 2007). However, behind the diverse range of themes there is a pattern: the focused fields are significantly different between countries, and between the diverse networks of neighbouring country collaborators (Yarime et al. 2010). Sustainability science provides information indispensible for solving the sustainability challenge. However, the perceptible trend towards a further fragmentation of research concerning the substance of sustainability might put this essential function at risk.

This review of the state of sustainability science focuses on the structures, methodology and paradigms of sustainability science, instead of highlighting the results of individual studies. As sustainability poses challenges to the scientific system and methodology as such, I will discuss specific traits required for a scientific analysis of sustainable development. Sustainability science can be conceptualized to comprise two elements, science for sustainability and science of sustainability. The following section takes a closer look at science for sustainability, a disciplinary-based, but interdisciplinarily-framed contribution to address key sustainability challenges like climate change and biodiversity loss, including much of basic science. I then introduce the science of sustainability, and describe reflexivity and applicability as its key characteristics. I go on to identify some research areas that are specific for sustainability science, and specific project management structures and processes. I describe means of achieving participation in day-to-day research, and the opportunities and risks, and conclude with an outlook for the whole field.

\section{SCIENCE FOR SUSTAINABILITY}

Science for sustainability is an attempt to strengthen the dialogue between society and science, and thus a service provided by science to society. It supports the search processes for sustainable solutions, helps assess the impacts of current decisions and identify the actions required for the future environment to reach a certain state. As it serves a purpose, the pursuit of sustainability, it is teleological, directed towards the goals of sustainable development. 'Although heterogeneous in scope and practice, the emerging research field mainly draws upon scholarly attempts that rethink interaction across domains and scales, primarily those between nature and society, science and democracy, the global and the local, as well as the past, the present and possible futures' (Jerneck et al. 2011, p. 2). This influences the methods applied, for instance the use of scenarios, a key means for analysing interactions. When used in scientific analyses, these are usually forecasting scenarios; trends are extrapolated while assuming some externally set events, and explore potential future impacts of action and inaction. However, science for sustainability also uses backcasting scenarios; ideal future states are described derived from stakeholder participation, and these scenarios are used to explore the measures needed to approach them (see Raskin et al. 2002 and Raskin 2008 as examples of this approach).

Science for sustainability can be monodisciplinary or multidisciplinary, but it must be at least 'interdisciplinarityready', conducted with the broader picture of sustainability in mind, and therefore ready for integration with results from other disciplines. In the case of multidisciplinary projects, this is an obvious condition of project success, and in all cases it is a criterion if a certain research undertaking qualifies as a contribution to science for sustainability.

\section{The challenge of interdisciplinarity}

As differences in ontology and epistemology constitute one of the main obstacles to the integration of knowledge across disciplines and social groups (Feyerabend 1975), real interdisciplinarity is a serious challenge for disciplinary research. It requires defining the research questions with a broader context in mind, and some knowledge about the methods and capabilities of other disciplines that could contribute complementary insight. This in turn requires 
a common vocabulary (Horwitz 2003; Bruce et al. 2004; Klein 2008). By interpreting what they observed against the background of their own discipline, Jerneck et al. (2011) illustrated the problems by demonstrating that social scientists may misinterpret the term 'uncertainty' in natural science debates as an indicator of scientific disagreements, not as an unavoidable data problem. Another example is the research on ecosystem services, the 'benefits that humans recognise as obtained from ecosystems that support, directly or indirectly, their survival and quality of life' (Harrington et al. 2010). Popularized by the Millennium Assessment (MA), which integrated social and biosciences and used the term as a metaphor to highlight the social importance of natural systems (MA 2005), it was turned into an operational economic concept by Costanza et al. (1997). Their calculated aggregate value of more than US\$ 30 trillion for the ecosystem services nature provides to humankind for free was widely used by conservationists to underpin their cause, but fiercely criticized by economists as 'bad science' (Ecological Economics 1998). Both economists and bioscientists seem to agree that accounting for ecosystem services is important, but both disciplines seem to be divided over whether monetary valuation is justifiable and useful (Burkhard et al. 2010; Spangenberg \& Settele 2010). Such divergence may be due to lack of clarity concerning diverging definitions of value and measurement between disciplines.

Thus, successful interdisciplinary communication requires its own dictionary of clearly defined terms. For disciplines whose object requires knowledge historically generated by other disciplines, this 'disciplinary multilingualism' (Spangenberg 2003), the mutual understanding of epistemologies and ontologies, becomes particularly important (Horwitz 2003). This minimum condition for successful collaboration has been called the 'basic law of interdisciplinarity': no discipline must build upon assumptions that are in flagrant contradiction to the established and undisputed body of knowledge of another discipline in charge of the issue at stake (Spangenberg 2006). Only then can incommensurable results be avoided, and the outcome of different projects used to develop a larger picture.

In science for sustainability, structure, method and content must differ fundamentally from most known science, as reductionist methods will not be enough to develop workable solutions to the sustainability challenge (Weinstein 2011). It is a challenge for researchers to admit that they can only gain partial knowledge of the object under analysis and that they are dependent on the contributions of other disciplines to build a more complete understanding. Even worse, as meaning is always context dependent, for any researcher the meaning of their results may change when embedded in the broader context of interdisciplinary research.

Science for sustainability answers society's questions, gives indications of the consequences of proposals under discussion and warns against ignored risks. This requires a placebased analysis of problems (with the global and intertemporal context in mind) as the basis for finding effective solutions.
Much of the scientific work labelled as sustainability science is at best interdisciplinarity-ready as I have defined it; it is undertaken in a rather traditional disciplinary setting, but with an enlarged horizon and dedication to make a difference. However, hoping that science for sustainability could serve as a method for integrating knowledge generated through essentially unchanged traditional science, that it can help solve sustainability problems, and that traditional science and technology could be the basis for a sustainable future, would underestimate the need for change in science for sustainability. Traditional science disciplines exhibit a lack of consistency in approaches to problem definitions and in the development of solution options between different disciplines that requires major adjustments in the context of science for sustainability (Kauffman 2009).

Thus far, much research on issues related to sustainable development has been conducted from a highly restricted view of both phenomena identification and 'problem solving' (Komiyama \& Takeuchi 2006). This is the domain of science for sustainability (see Table 1 for difference between science for sustainability and science of sustainability). Problem solving approaches seek to find answers to problems within a particular perspective, accepting pre-existing power relations and institutions. Particular problems are reduced to a limited number of variables, which are studied with precision and subsequently manipulated.

\section{THE SCIENCE OF SUSTAINABILITY}

While there has been unabated attention to sustainability science for many years now, much less work has been dedicated to understanding the specifics of sustainability as such, and the complexities of the interaction of evolving systems.

The science of sustainability addresses what Clark (2007) has called the 'core sustainability science research program', namely 'understanding the complex dynamics that arise from interactions between human and environmental systems'. In the quest for applicable and problem solving solutions, it searches for a generalizable scientific understanding of sustainability, with research based on conceptual models and methods built at the interface of disciplines. Following Einstein's dictum that a problem cannot be solved by the same mindset that helped create it, the science of sustainability critically reflects on the imperatives of modern science that have existed since Francis Bacon, René Descartes and Isaac Newton. Furthermore, what is the 'best available' information changes with the fact that the information should be applicable, and with the purpose for which the information is used. Thus the analysis must be open to any and all methods that add insights (Ascher 2007).

As multiple values are involved or at least affected in virtually every significant issue, the analysis of the situation must include clarifying the values of stakeholders (for example by discourses and participation), and those of the analyst. Furthermore, lack of obvious cause-effect chains 
Table 1 Two branches of sustainability science and their distinctive features. Mode-1 science is completely monodisciplinary and academic in nature, whereas in mode- 2 science research is but one component of an extensive process of knowledge production

\begin{tabular}{ll}
\hline \hline Science for sustainability & Science of sustainability \\
\hline Mode-1 sustainability science & Mode-2 sustainability science \\
Monodisciplinary & Interdisciplinary and transdisciplinary \\
Highly focused & Broadly based \\
Normal science & Post-normal science \\
Curiosity driven and problem solving & Critical research \\
Academic & Academic and social \\
Academic peers & Extended peer community \\
Certainty & Uncertainty and ignorance \\
Hierarchical logic & Relational logic \\
Scientific proofs, unequivocal results & Discursive processes, ranges of options \\
Top-down, command and control & Discursive process of opening up and closing down \\
Stakeholders affected & Stakeholders involved \\
\hline \hline
\end{tabular}

can make existing institutions incapable of dealing with the challenge of future impacts, regardless of the scientific information available (Jerneck et al. 2011). Thus the science of sustainability must necessarily not only embrace natural sciences and economics, but also social sciences contributing to such analysis, for instance political science and sociology. Psychology and anthropology can help understanding of human decision-making patterns, and revealing the importance of social reciprocity offers an antidote to the kind of selfish rationality assumptions on which economics is based, thus illuminating preoccupations with sustainability and coexistence in industrial and postindustrial societies. The social sciences and humanities, with their reflective, reflexive and critical approaches, can introduce questions about the basic assumptions of modern societies (Jerneck et al. 2011). The integration effort must include engineering; it should 'bridge the gulf between the detached practice of scholarship and the engaged practice of engineering and management' (Weinstein 2011, p. 3). Most importantly, the science of sustainability also requires quality assurance through extended participation of practitioners and users of the information provided, integrating empirical and anecdotal evidence into the more theoretical frameworks of different disciplines. This approach requires the discussion of and an agreement on priorities based upon the diverse aspects involved.

The challenge when integrating the diverse input is not isolating one or a few more important factors as in the usual reductionist approach, but integrating the relevant factors into a multifaceted picture (Ascher 2007; see also Table 1).

The science of sustainability requires not only rethinking the mode of science and its methodologies, but also needs bridging concepts between different disciplines linking biosciences and geosciences with social and economic sciences. Prominent examples amongst those that developed over the last 20 years are ecological economics (Martinez-Alier 1987; Söderbaum 2000), industrial ecology (Ayres \& Simonis 1994), social ecology (Fischer-Kowalski 1996); transition theory (Rotmans et al. 2001), resilience theory (Berkes et al. 2000), world system analysis (Wallerstein 1974), technology assessment and science and technology studies (Kastenhofer et al. 2011). In many cases, however, these concepts and theories are applied in a static fashion, treating a certain state of the respective other systems as an external constraint in system analysis. The understanding of the dynamics and mutual dependencies of co-evolving systems, and how the resilience of the metasystem of 'society in nature' depends on the respective resilience and dynamics of the subsystems, is still in its infancy (Jerneck et al. 2011).

\section{Reflexivity}

As the challenges addressed are, to a significant extent, the result of earlier progress in science and technology, the science of sustainability must necessarily be reflexive, not only regarding the results of science and engineering and their application, but also regarding the paradigms endorsed and the kind of questions asked, as these have a significant influence on the world view of modern societies. Thus science of sustainability is a 'critical theory', reflective on the process of theorizing itself, asking how the situation came about, calling contemporary institutions and power relations into question, and allowing for normative choices of alternatives (Jerneck et al. 2011, with reference to Cox 1981).

If this reflection includes a critical assessment of the role and impact of the investigator and his or her discipline, it is a reflexive process. Reflexivity in this sense is a social theory concept describing the capacity of an individual agent to act against influences of socialization and social structure, based on critical self assessment. It questions assumptions such as the objectivity of the observer, the value neutrality of science, the kinds of values inherited and possible alternatives, and the ability to predict future events. It requires the acceptance of uncertainty, ignorance and the impossibility of knowing all relevant facts about evolving systems, and that the existence of emergent system properties makes micro-level explanations of macro-level system behaviour impossible (in physics and bio$\log y$ as much as in sociology and economics). In this context, uncertainty is distinguished from certainty as a situation where future events and their impacts are fully known, and from risk, when the probability of future events and their impacts are well known. It is defined as the situation when possible future events are known but not their impacts. Ignorance is then the 
situation when neither the range of possible events nor their impacts are known (van der Sluijs 2002).

Reflexivity also accepts that there are other kinds of knowledge apart from scientific knowledge which may be of similar relevance for decision making. It also includes a critical reflection of the respective roles of scientific minorities and majorities in science and society, which can be quite different; in economics, for instance, the mainstream dominates the public perception to the exclusion of alternative views, while in climate science the small minority negating human-made climate change may dominate the mainstream in public perception and political effect, at least in some countries.

The prevailing reluctance to enter a process of reflexive assessment of both a personal role and that of the respective discipline as a whole stems not only from individual inertia: changing the context, reinterpreting disciplinary findings and questioning assumptions or axioms means challenging the specific construction of reality of the respective discipline. This construction entails necessarily a reduction of complexity as compared to reality, accepting the objects of interest are made accessible to the set of instruments and methods a discipline commands. Questioning this setting can lead to alienation within the respective scientific community. It is the disciplinary reputation, gained by disciplinary work published in disciplinary journals and rewarded with prominent positions in disciplinary societies, which is the basis of reputation, influence, funding and often also of selfesteem. The disciplinary structure of science (for example faculties, institutes, PhDs, journals and societies) is a major obstacle to interdisciplinary and transdisciplinary research: although examples of interdisciplinarity can be found in each of these categories, disciplinary structures still dominate. The continued calls for multidisciplinary, interdisciplinary and transdisciplinary collaboration indicate that such collaboration is both technically difficult and still runs counter to the reward structures in many fields (Ascher 2007).

The need for reflexivity in the science of sustainability applies not only to the research attitudes and processes, but also to their results. Science-based interventions in complex natural and social systems can constitute, in themselves, a selfrenewing source of problems. The science of sustainability needs to counteract these challenges by issue-driven and reflexive research, beyond the prevailing curiosity-generated or mission-oriented work. Consequently, ex-ante impact assessments are an indispensible tool for the science of sustainability.

\section{Applicability: the science-policy interface concept}

Sustainability science is applied science; all its results should be instrumental, directly or indirectly, in solving sustainability problems; this orientation influences the choice of subjects and the methodology. When it comes to the interpretation of results and their application, however, there is a difference between science for and the science of sustainability. Most of the former leans more to the traditional scientific paradigms, comprises important fields of basic research and applies the quality criteria of the respective scientific communities by vigorously trying to avoid 'type 1 errors', in other words not to corroborate false positives. This necessarily goes at the expense of creating 'type 2 errors', in other words producing false negatives. The fact that each successive assessment published by the Intergovernmental Panel on Climate Change (IPCC) has been more alarming than the previous one illustrates the effects of this prioritization, although the IPCC has tried to address the problem by publishing a range of results classified according to their probability (IPCC 2007).

Decision makers and the public at large follow a different approach: they need to balance the risk of falling victim to either error. Consequently, their standard is not scientific proof, but a quality of information solid enough to act upon. This may be the case long before a proof is available, if ever, and constitutes the essence of the precautionary principle. Thus the definition of what is valid information is not identical in the politics and science subsystems of society, and the applicability of science of sustainability research results requires their presentation to follow the logic of the political and social system, not the imperatives of the scientific method. It is not only that a simplistic 'science guides policy' approach would not work, it could even be misguiding, as scientific rigour could prevent early warnings and undermine precaution.

Instead of claiming the lead in policy decisions, the science of sustainability is deliberately restricted to contributing to science-policy interfaces, social processes where the exchange between scientists, decision makers and stakeholders takes place. At best, such processes develop into real discourses, allowing for a joint construction of knowledge and perceptions (that is, subjective interpretations) of reality (van den Hove 2007) and constituting the 'truth of the matter' for a historical moment (Foucault et al. 1992). This exchange is a mutual process; in effective science-policy interfaces it includes the notions that (1) the scientific information is relevant to policy decisions, (2) this relevance is defined according to the logic of societal decision making, (3) it is explicit, formulated in the language of potential users and thus obvious to them, (4) decision makers formulate their information demands in a way accessible to scientists, (5) it addresses those able to provide the relevant information, and (6) it takes into account the information (not necessarily following the recommendations) in their deliberations. Science of sustainability, characterized by multiple disciplines, dimensions, perspectives, spatial and temporal scales, and based on diverse knowledge sources, tools and methods, is not easily integrated into such exchange processes.

\section{Meta level frameworks}

The emergence of science of sustainability can be understood as part of a larger trend in the evolution of science (Spangenberg \& O'Connor 2010). It is part of a paradigm 
shift emerging 'from a scientific sub-current that characterises the evolution of science in general - a shift from mode- 1 to mode-2 science' (Martens 2006, p. 38). In this terminology, mode- 1 science is completely monodisciplinary and academic in nature, whereas in mode- 2 science research is but one component of an extensive process of knowledge production (Gibbons et al. 1994; Nowotny et al. 2001).

Another characterization of the science of sustainability is related to the perceived level of certainty of scientific results available in a given decision-making situation, and the methods of generating them. Situations when scientific input is needed are often described as cases where stakes are high, decisions urgent, facts uncertain and values disputed. These are the characteristics requiring the use of 'post-normal science' (Funtowicz \& Ravetz 1993), which differs from the 'normal science' approach of 'puzzle solving' (Kuhn 1962) where new insights are generated based on a limited set of rules and assumptions constituting the disciplinary paradigms defining a particular world view. In situations where values are disputed, goals conflicting and choices difficult, methods are not neutral. Thus scholars in post-normal science have to make the reasons for their method choices transparent and the inherent assumptions explicit when dealing with stakeholders (Jerneck et al. 2011).

Post-normal science deals with uncertainty and ignorance, and highlights the need for participatory processes in generating a joint knowledge base as a foundation of precautionary policies (Funtowicz et al. 1998). While most science for sustainability is mode- 1 normal science, the science of sustainability is mode- 2 post-normal science. A specific challenge is that this approach differs from normal science in relation to recognizing phenomena, analysing mechanisms and application to sustainability problems. Instead of a stepwise shift from basic to applied science, or from descriptive via analytical to synthetic science (Hohlfeld 1988), solutions to problems may have to be sought before those problems have been sufficiently analysed or even identified (Komiyama \& Takeuchi 2006). Science of sustainability is 'critical research', in that it includes making the 'great narratives' or 'preanalytic visions' (Daly 1990) underlying research explicit, deconstructing them, unlearning what was considered selfevident in a mode-1 normal science context, and new learning in an extended social context (see Table 1).

A similar distinction to that between mode- 1 and mode- 2 science has been suggested for the level of implementation. First order governance as a top-down management structure effective in systems where any action has a clearly predictable result can be distinguished from second order governance suitable for complex systems and in the case of inherent uncertainty (Kemp et al. 2005). The latter takes into account the distributed knowledge in complex systems and consists of iterative discursive processes of opening-up and closingdown, of gathering input and of synthesizing. This focus on the kind of decision-making process reflects what is well known in political science; that the process as such influences the outcome and the effectiveness of the policy options derived
(Ascher 2007). As the scientific input is one of the important sources of information, albeit not the only one in the science of sustainability concept, the analyst must be capable of recognizing the policy situation within which the scientific information can and will be used in different ways, according to particular interests. Consequently, 'analysts must not only be experts in the policy process, but also experts of the policy process' (Ascher 2007, p. 146, emphasis by the author).

\section{A NEW FOCUS}

Both branches of sustainability science contribute to the key research issues. For instance, the IPCC (2007) assessment report and the Stieglitz/Sen/Fitoussi report on welfare measurement (Stiglitz et al. 2009), deal with issues where basic information is missing and science for sustainability has important gaps to fill. This knowledge is also needed in order to identify potential remedies for the problems motivating the research or at least the research funding in the science of sustainability.

The ISCU (2002, p. 9-10) identified three core themes for sustainability science which are items of ongoing research but still pose very substantial questions:

- 'Adaptiveness, vulnerability and resilience in complex socio-ecological systems: Sustainability depends on building and maintaining the adaptive capacity needed to deal with the shocks, surprises and longer term structural transformations that are increasingly characterising our world. Existing understanding of adaptiveness, vulnerability and resilience has tended to adopt either nature- or society-oriented views of the world. Needed are new tools and concepts that facilitate management of these properties for the tightly linked socio-ecological systems that areat the heart of the sustainability challenge. Such understanding will have to address the embedding of of particular socio-ecological systems - and their adaptive capacity - within larger regional and global contexts.

- sustainability in complex production-consumption systems: There have long been calls for deeper understanding of how the environmental impacts of production, on the one hand, and consumption, on the other, can be lowered. An important insight emerging from our consultations is that the greater need is for an integrated understanding of the relations between consumption and production. These are becoming increasingly complex as ass globalization increasingly separates locations at which production and consumption occur. Incentives and technologies work at both ends of the production-consumption chain, and an integrated understanding of their impacts on sustainability is badly needed as a guide for targeting policy.

- institutions for sustainable development: The systems of rules, procedures and expectations that guide social interactions (including the prevailing mode of governance) shape both the challenges of, and the 
opportunities for, sustainability. Experience reviewed at the Mexico City workshop makes it that the ability of our institutions to deal with the cross-scale aspects of interactions among politics, markets and knowledge will be especially important in determining the prospects for sustainability [...]'

Since 2002, considerable research has been devoted to these issues, but many questions remain unanswered. With regard to research on the interaction of society and economy, value systems and power structures and their interaction with environmental systems and sustainability objectives, the Millennium Ecosystem Assessment (MA 2005), the IPCC's $4^{\text {th }}$ Assessment Report (IPCC 2007) and the UNEP GEO 4 report (UNEP [United Nations Environment Programme] 2007) are outstanding examples.

Sustainable consumption and production (SCP) is still a central policy concern, highlighted by discussion of a 10year framework programme on this issue at the 2011 United Nations (UN) Commission on Sustainable Development meeting. SCP research has revealed that consumers are not driving the economy from the demand side; neither are businesses independent from consumers. Habits, attitudes and preferences of consumers and producers shape the global production chain, with sustainable development an explicit objective on either side. Unless quality of life and sustainable consumption can be reconciled, consumers will show reservations, and provided sustainability provides no opportunities for greater or more secure profits than unsustainable behaviour, business will remain sceptical towards SCP (for an overview see Reisch \& Røpke 2004).

'Institutions for sustainable development' is one of the two central themes for the 2012 World Summit on Sustainable Development. Here progress on the ICSU demand 'to identify how and under what conditions some institutions advance sustainability goals better than others, and above all to help the groups running the existing institutions to learn from one another' (ICSU et al. 2002, p. 10) has been slow. While education and capacity building will be essential to bridge the knowledge gap between what is known and the unknown, new transdisciplinary approaches will be necessary. Systems for monitoring the sustainability performance of institutions and governance models are only embryonic, and existing indicator systems tend to ignore core aspects of cultural diversity, power structures and in particular gender discrimination (Spangenberg 2007; Zuindeau 2007). Gender mainstreaming in scientific staff and research topics offers significant potential for enhancing the human knowledge base.

\section{A new management approach}

Balancing the approaches, making scientific results meaningful by involving non-scientific expertise without losing the scientific quality, is an indispensible part of the science of sustainability and an art of its own. It requires a kind of sensitivity and diplomacy that scientists do not necessarily acquire in their education.

Like most of interdisciplinary science, the science of sustainability requires a different management model of research processes. Whereas in single discipline projects the coordinator has to be an acknowledged scientist who understands what is going on in a project, and who can rely on the disciplinary rules and mechanisms comprising data quality, control and publication, this is not the case in interdisciplinary projects. Creating space for reflection and initiating interdisciplinary and transdisciplinary discourses, and enriching the research without disturbing the research process, requires a particular type of project coordination, including a broad knowledge of different methodologies and scientific cultures. To facilitate progress towards integration, the respective coordination team has to invest certain, albeit variable, amounts of energy to help initiate interdisciplinary and transdisciplinary processes. The challenge is not to make this a constant energy input, but to make it a catalytic process that becomes self-sustaining, only occasionally needing stimulation. However, if the project structures, disciplines or character of the actors involved prevent catalytic initiation and self-sustained progress within the interdisciplinary or transdisciplinary work plan, then the energy flow from the coordination can only affect a few scholars, becomes quickly depleted and would not sustain the process (Settele et al. 2010a). Besides the personalities involved, it is thus the combination of formal structures and applied, often pragmatic, management that makes the difference for integrated interdisciplinary projects in sustainability science (Spangenberg 2003).

The structure of any sustainability science project should be conceptualized not as static, but as a dynamic process with a clear vision but no final state defined in detail. This combination of clear objectives and flexibility in structure and content should be backed by a number of contingency rules, namely institutional arrangements not influencing the everyday work but providing means to handle problems should something should go wrong, such as missing deadlines, overspending resources or other problems affecting delivery of the work plan. In the best of cases, these fall-back positions need not be activated throughout a project, but their very existence can contribute to smooth implementation of a flexible and dynamic work plan (Settele et al. 2010b).

However, the necessary flexibility is not only a matter of project design, but also of restrictions imposed by the donors and of project size; although small and medium scale projects are important to deal with specific research questions, only large projects involving hundreds of scientists over an extended period offer the creative space and opportunity for exchange between disciplines that can lead to the definition of new interdisciplinary research questions and intercultural learning between different domains of science and humanities regarding methods and research approaches (Settele et al. 2007, 2008). These processes are time consuming, and although most donor agencies 
consider interdisciplinarity as added value, they are hardly ever ready to fund this extra effort, the development of understanding without any results being presented. The permanent underfunding of processes for sharing world views, creating understanding and establishing a common language is one of the reasons why, regardless of call texts and report wording, interdisciplinarity all too often does not materialize in research reality (Spangenberg 2003).

Thus the need for new attitudes also applies to those funding research. However, such a development requires sufficient care not to extradite science to partisan interests, as occurs today with the preference for research that benefits business.

\section{Science in society: extended peer communities}

For science to be geared to problem solving and dedicated to supporting change towards sustainability, stakeholder participation is indispensible. One key reason is that the effects of implementing science-based measures will frequently emerge outside the individual scientist's realm and field of competence, but will still be partly the responsibility of science. The concept of scientific communication as a oneway traffic of information from experts to decision makers and the public at large is old-fashioned. It has to be replaced by a notion of partnership through reciprocal learning by all those involved and affected. This implies involvement of both the public and decision makers in the quality assurance and assessment of scientific and technological innovation: every stakeholder becomes a peer.

The broadening of peer communities, including different forms of ex ante, project integrated and ex post involvement generates a number of benefits and risks that vary among the forms of stakeholder participation. Opening the research process to interdisciplinary cooperation can be extremely fruitful, provided all disciplines involved are ready to accept their limited competence and thus their role as contributors amongst equals. This always takes time to develop, but once a common language has emerged, the effect of this new setting is a richer and more differentiated view and results have a higher degree of political relevance.

In extending the knowledge base stepwise, the first group to be involved is external experts. If properly chosen, they can provide valuable input, but pose a certain risk, as they have not undergone the mutual acceptability-enhancing process upon which interdisciplinarity is based. The form of involvement can vary, as can the stage and duration of their involvement. All options have both advantages and disadvantages (Table 2).

The final step is including non-scientific knowledge. In this case, scientists are recipients demanding information from the stakeholders they invite to participate, while the non-scientists are donors of their knowledge and time; they are usually unpaid, as unlike other experts, technology providers and consultants, they are usually not eligible for receiving remuneration from research funds, irrespective of their importance for the project success. Consequently, they will, to a large degree, determine the rules of their involvement with regard to time and the choice of the issues that are relevant to them.

Unlike advisory boards, which can only articulate recommendations, steering committees have steering power, that is they can take decisions binding the project management (and thus they also have a higher level of responsibility).

Knowledge of problem relevance is no monopoly of science, and even less so of any discipline. Transdisciplinarity, including tacit knowledge and experience-based insights, simply means that all knowledge relevant to the solution of a problem is integrated; failure to do so would mean conducting research while ignoring relevant information. This 'extended peer community' approach is an essential constituent of science of sustainability as a post-normal science (Funtowicz \& Ravetz 1993).

Stakeholders must be involved on an equal footing, albeit not equally in all phases of the work. Potential positive results include, but are not limited to, a better definition of research questions relevant to society, broader definition of strategies to be pursued, improved policy suggestions grounded in reality and enhanced support for proposals through a feeling of ownership developed in the process. Conversely, there are also risks, such as short term perspectives if the discourse is dominated by acute problems, blockades of proposals deemed inadequate or inappropriate or taboo at the time and interventions designed to enforce desired results from the research process.

Defining the research questions should be a joint exercise, the relevance of a task being decided by stakeholders with scientists possibly participating in their capacity as citizens, rather than because of their scientific expertise. However, regarding the methodology and approval of scientific work, scientists must play the decisive role. They have to make their choice of methods explicit and justify the appropriateness of their approaches; methods are not neutral. This is part of the project planning phase, but need not necessarily be repeated at every step of a project. The ideal project would include: stakeholder involvement in definition of research questions to enhance the relevance of research; regular consultation during the research process providing peers the opportunity to have a real impact on the research; joint evaluation of interim results and incorporation of the outcome in the research process to help assure quality and relevance of the results; peer preassessment of final results to create a feeling of ownership; and the common presentation of results to improve the credibility of the research work, enhance outreach and acceptability.

Organizing an information transfer or dissemination process according to actors' needs and involving project staff together with the extended peer group can foster the implementation of project results, but only if decision makers accept their relevance. For this crucial step, the composition of the peer group and the degree to which they identify with the project and its outcomes can make a decisive difference.

The involvement of non-scientists as information sources does not require the strict methodological and institutional 
Table 2 Potential advantages and disadvantages of involving external sources of knowledge in peer communities.

\begin{tabular}{|c|c|c|c|}
\hline Measure & & Positive characteristics & Negative characteristics \\
\hline \multirow[t]{3}{*}{$\begin{array}{l}\text { Expert knowledge: extended } \\
\text { scientific peer communities }\end{array}$} & Advisory boards & $\begin{array}{l}\text { Continuous advice throughout } \\
\text { the project, familiarity with } \\
\text { details of the project }\end{array}$ & $\begin{array}{l}\text { Positive group dynamics may } \\
\text { drive project. Conflicts (e.g. } \\
\text { between disciplines) lead to } \\
\text { deadlocks }\end{array}$ \\
\hline & Hearings & $\begin{array}{l}\text { Situation specific advice, but out } \\
\text { of the project context }\end{array}$ & $\begin{array}{l}\text { Interdisciplinarity easily achieved, } \\
\text { but hardly integration }\end{array}$ \\
\hline & Internet & Broad access to external expertise & Low selectivity of participation \\
\hline \multirow[t]{3}{*}{$\begin{array}{l}\text { Lay knowledge: extended peer } \\
\text { communities involving } \\
\text { non-scientific experts }\end{array}$} & Steering committees & $\begin{array}{l}\text { Safeguards relevance of research } \\
\text { issues and the credibility of the } \\
\text { methodologies applied }\end{array}$ & $\begin{array}{l}\text { Can prescribe assumptions and } \\
\text { methodologies not suitable } \\
\text { from a scientific point of view }\end{array}$ \\
\hline & Advisory boards & $\begin{array}{l}\text { Selective involvement to discuss } \\
\text { non-scientific questions like } \\
\text { research objective and relevance }\end{array}$ & $\begin{array}{l}\text { Individual positions rather than } \\
\text { integrated group assessment, } \\
\text { politically heterogeneous }\end{array}$ \\
\hline & Consultation processes & $\begin{array}{l}\text { Broad access to external expertise } \\
\text { of selected sectors }\end{array}$ & $\begin{array}{l}\text { Not necessarily coherent } \\
\text { suggestions }\end{array}$ \\
\hline
\end{tabular}

framework of science, but the development of common sense arguments and plain language communication skills, and understanding of the scientific meaning of information provided in a non-scientific language. Again, such involvement can take different forms, and the positive potentials have to be weighed against the risks when choosing a method for a specific context.

To maintain the external participants' motivation, both scientific and societal experts must be consulted at moments during the research process where their input really makes a difference, for instance regarding future research questions or the use of previous results. This includes interim reports, reviews, consultative meetings for planning new project phases, but also covers a readiness to return to what has been done and fill gaps identified by the non-scientific advisors.

For scientists, this can be a serious challenge, as the criteria applied by non-scientists may differ significantly from those used in research processes. Possible sources of conflict include, but are not restricted to, the political relevance of the research results, in other words the possibility of using results to enact or avoid change ('if we can't do anything about it, why go into details?'), or public sensitivity to the presentation of results ('this does not mean anything to me' versus 'if you emphasize that point, everybody will listen'). There is not necessarily an immediate match between paying tribute to public sensitivity and the priorities derived from a particular piece of research, whether intermediate or final.

Developing the proper structure of project design and management, of experimental work, desktop research and discourses, and providing the necessary coherence and balance will be challenges for all future sustainability science projects.

Finally, in the dissemination process after a project has been concluded, the issue is no longer to involve external partners to steer the project, but to present the results in a way most meaningful to the outside world (although a good discussion may always generate new research questions).

In this phase, the scientists and the extended peer group set the agenda. They invite different audiences that they consider relevant and accessible (here the peers are again crucial) to insert their insights into societal decision-making processes. This may be done by the donor rather than by the scientists, which underlines the role of donors as relevant stakeholders and thus peers. The outreach requires a high level of flexibility to gain the attention of the different target audiences (Table 3). As no opportunity exists to create a feeling of ownership in a finalized product, outsiders' fascination emerges from applications rather than from content. However, as the potential applications are as different as the possible target audiences, tailor-made presentations to specific target groups are the most promising way to proceed; again this is a skill not necessarily learnt in the academic education process.

\section{OUTLOOK}

In many European countries, public trust in science and technology seems have decreased in the last 20 years (European Commission 2010b). Although the doubts are not always expressed in ways that are scientifically sophisticated, if they deepen to a broad and chronic mistrust they can contribute to a falsification of any vision of a key role for science in a 'knowledge based society'. One reason for this dissatisfaction is the experience with mode- 1 science and first order governance, such as cost-benefit analysis based planning or science-based safety standards. No matter how well conducted, they are a defective basis for public and private decision-making, as neither the choice of questions asked nor the methods used generate answers provide a robust basis for the necessary sustainability transition (Raskin 2008).

Two obvious tasks are addressing pressing sustainability problems by filling gaps in the research landscape and sensitively responding to public sustainability concerns. Sustainability science, by opening up to societal demands and concerns, can provide crucial contributions to re-establishing the necessary level of trust, but this will be impossible without changes in the overall system of scientific conduct and institutions. 
Table 3 Implementation of knowledge and transfer processes.

\begin{tabular}{lcc}
\hline \hline Measure & \multicolumn{1}{c}{ Positive effects } & Negative effects \\
\hline $\begin{array}{l}\text { User-producer- } \\
\text { networks } \\
\text { Mixed boards }\end{array}$ & $\begin{array}{c}\text { Creates trust and familiarity with each others } \\
\text { problems through continuous exchange } \\
\text { Combines interdisciplinary scientific and } \\
\text { stakeholder input to the project }\end{array}$ & $\begin{array}{c}\text { Risk of in-breeding } \\
\text { Can end up in deadlocks if too controversial } \\
\text { positions; complementary boards can be } \\
\text { more successful }\end{array}$ \\
Presentations & To decision makers: focus on results & $\begin{array}{c}\text { Risk of missing caveats, oversimplification of } \\
\text { decision basis }\end{array}$ \\
& $\begin{array}{l}\text { To scientists: focus on methodology } \\
\text { To lay people: focus on the meaning for the } \\
\text { everyday life, needs a rather different } \\
\text { language }\end{array}$ & $\begin{array}{c}\text { Risks both, lack of understanding due to } \\
\text { complexity, and feeling of being excluded } \\
\text { from the political discourse }\end{array}$ \\
\hline \hline
\end{tabular}

Environmental research needs to include knowledge and tools for improved understanding of ecosystem processes, including the role of human agency, effective ecosystem management at the landscape scale and monitoring programmes detecting change against background variability (Jerneck et al. 2011). On the social side, an improved understanding of societal preference change mechanisms is crucial for the transition towards sustainability, in particular the role of collective entities in shaping behaviour. Regarding economics, sustainability macroeconomics is still in its infancy.

For the future, new vital sustainability science themes include biodiversity, restoration ecology, conservation biology, climatic and geochemical cycles, limits to resource availability and their economic and social impacts, socioeconomics and technical systems dynamic analysis (Jerneck et al. 2011). There is a clear difference between this and current research clusters and their themes, and sustainability science will have to refocus accordingly.

Despite profound changes in nature and society, the disciplinary organization of scientific knowledge production remains largely unchanged, although systemic sustainability research is having a strong influence on academia (Jerneck et al. 2011). Sustainability science requires re-engineering the fabric of science for all domains of science and engineering, including the respective standard methodologies and institutions. If successfully implemented, the value of science would be significantly increased for society, public and scientific credibility enhanced and a vast range of new and fascinating research questions would result. For scientists, the challenge of sustainability is an unmissable opportunity .

The promotion of sustainability science requires procedures for evaluating scientific and technological contributions against criteria for sustainability. Neither the advance of science and technology itself nor the current widening of competitive markets can be expected to promote, as if 'naturally', a path of sustainable development (Spangenberg 2010). On the contrary, the short-term orientation and the mixtures of commercial, military and other preoccupations that motivate much of the sciencebased technology development are most often controversial to a sustainability perspective based on peace, justice and environmentally sound development (Funtowicz et al. 1999). There is an undeniable risk of undersupplying public goods essential to sustainable development when too much of the research and development talent is in private hands and focused on delivering private value. Science for sustainable development is science facing its public responsibility, for researchers, institutes and donors. It is time for a change.

\section{ACKNOWLEDGEMENTS}

I acknowledge past and current colleagues at the Wuppertal Institute, the Helmholtz Centre for Environment Research and the Sustainable Europe Research Institute for joint reflection about sustainability science. My special thanks to Frieder Otto Wolf and Josef Settele, as coordinators respectively of the SuStrat Sustainability Strategies and the ALARM projects. This work was funded by the European Commission.

\section{References}

Allen, P.M. (2001) The dynamics of knowledge and ignorance: learning the new systems science. In: Integrative Systems Approaches to Natural and Social Dynamics, ed. H.M.W. Matthies \& J. Kriz, pp. 3-30. Berlin and Heidelberg, Germany and New York, NY, USA: Springer.

Ascher, W. (2007) Policy sciences contributions to analysis to promote sustainability. Sustainability Science 2(2): 141-49.

Ayres, R.U. \& Simonis, U.E., eds (1994) Industrial Metabolism. Restructuring for Sustainable Development. Tokyo, Japan, New York, NY, USA and Paris, France: United Nations University Press.

Berkes, F., Folke, C. \& Colding, J. (2000) Linking Social and Ecological Systems: Management Practices and Social Mechanisms for Building Resilience. Cambridge, UK: Cambridge University Press.

Bossel, H. (1996) Deriving indicators of sustainable development. Environmental Modelling and Assessment 1(4): 193-218.

Bossel, H. (1998) Earth at a Crossroads. Paths to a Sustainable Future. Cambridge, UK: Cambridge University Press.

Bruce, A., Lyal, C., Tait, J. \& Williams, R. (2004) Interdisciplinary integration in Europe. Futures 36(4): 457-70. 
Burkhard, B., Petrosillo, I. \& Costanza, R., eds (2010) Ecological Complexity, special issue Ecosystem Services: Bridging Ecology, Economy and Social Sciences. Ecological Complexity 7(3): 257420.

Clark, W.C. (2007) Sustainability science: a room of its own. Proceedings of the National Academy of Sciences USA 104(6): 173738.

Clark, W.C. \& Dickson, N.M. (2003) Sustainability science: the emerging research program. Proceedings of the National Academy of Sciences USA 100(14): 8059.

Costanza, R., d'Arge, R., de Groot, R., Farber, S., Grasso, M., Hannon, B., Limburg, K., Naeem, S., O'Neill, R.V., Paruelo, J., Raskin, R.G., Sutton, P. \& van den Belt, M. (1997) The value of the world's ecosystem services and natural capital. Nature 387 : 253-60.

Cox, R.W. (1981) Social forces, states and world orders: beyond international relations theory. Millennium. Fournal of International Studies 10(2): 126-55.

Daly, H.E. \& Cobb Jr, J.B. with contributions by Cobb, C.W. (1990) For the Common Good: Redirecting the Economy Tomards Community, the Environment and a Sustainable Future. London, UK: Green Print.

Eckersley, R. (2006) Progress, sustainability and human well-being: is a new worldview emerging? International Journal of Innovation and Sustainable Development 1(4): 304-17.

Ecological Economics (1998) Special issue on the Value of Ecosystem Services. Ecological Economics 25(1): 1-142.

European Commission (2010a) Europe 2020. A European strategy for smart, sustainable and inclusive growth. Report COM(2010)202 fin. European Commission, Brussels, Belgium.

European Commission (2010b) Special Eurobarometer science and technology report [www document]. URL: http://ec.europa. eu/public_opinion/archives/ebs/ebs_340_en.pdf

Feyerabend, P.K. (1975) Against Methodology. London, UK: New Left Books.

Fischer-Kowalski, M. (1996) Society's metabolism: on the childhood and adolescence of a rising conceptual star. In: International Handbook of Environmental Sociology, ed. M. Redclift \& G. Woodgate, pp. 119-137. Cheltenham, UK: Edward Elgar Publishing.

Foucault, M., Seitter, W., Konersmann, R. (1992) Die Ordnung des Diskurses. Frankfurt/Main, Germany: Fischer Taschenbuch Verlag.

Funtowicz, S.O. \& Ravetz, J.R. (1993) Science for the post-normal age. Futures 25: 739-55.

Funtowicz, S.O., O’Connor, M. \& Ravetz, J.R. (1999) Scientific communication, international cooperation and capacity building for sustainable development. International fournal of Sustainable Development 2(3): 363-8.

Funtowicz, S.O., Ravetz, J.R. \& O'Connor, M. (1998) Challenges in the use of science for sustainable development. International Fournal of Sustainable Development 1(1): 1-10.

Gibbons, M., Limoges, C., Nowotny, H., Schwartzman, S., Scott, P. \& Trow, M. (1997) The Nem Production of Knowledge: the Dynamics of Science and Research in Contemporary Societies. London, UK; Thousand Oaks, CA, USA: Sage Publications.

Harrington, R., Anton, C., Dawson, T., de Bello, F., Feld, C., Haslett, J., Kluvánkova-Oravská, T., Kontogianni, A., Lavorel, S., Luck, G., Rounsevell, M., Samways, M., Settele, J., Skourtos, M., Spangenberg, J., Vandewalle, M., Zobel, M. \& Harrison,
P. (2010) Ecosystem services and biodiversity conservation: concepts and a glossary. Biodiversity and Conservation: 19(10): 2773-2790.

Hartmuth, G., Huber, K. \& Rink, D. (2008) Operationalization and contextualization of sustainability at the local level. Sustainable Development 16(4): 261-70.

Hohlfeld, R. (1988) Biologie als Ingenieurskunst. Zur Dialektik von Naturbeherrschung und synthetischer Biologie. Ästhetik und Kommunikation 18(69): 17-39.

Horwitz, A.R. (2003) Building bridges through collaboration-a pathway for interdisciplinary research. Trends in Cell Biology 13(1): 2-3.

ICSU, ed. (2002) Science and Technology for Sustainable Development. ICSU Series on Science for Sustainable Development No. 9. Paris, France: ICSU.

IPCC (2007) Climate Change 2007: Impacts, Adaptation and Vulnerability. Working Group II Contribution to the IPCC Fourth Assessment Report. Geneva, Switzerland: IPCC.

IUCN, UNEP \& WWF (World Wildlife Fund) (1991) Caring for the Earth: a Strategy for Sustainable Living. Gland, Switzerland: IUCN

Jerneck, A., Olsson, L., Ness, B., Anderberg, S., Baier, M., Clark, E., Hickler, T., Hornborg, A., Kronsell, A. \& Lövbrand, E. (2011) Structuring sustainability science. Sustainability Science 6(1): 114.

Kajikawa, Y., Ohno, J., Takeda, Y., Matsushima, K. \& Komiyama, H. (2007) Creating an academic landscape of sustainability science: an analysis of the citation network. Sustainability Science 2(2): 22131.

Kastenhofer, K., Bechtold, U. \& Wilfing, H. (2011) Sustaining sustainability science: the role of established inter-disciplines. Ecological Economics 70(4): 835-43.

Kates, R.W., Clark, W.C., Corell, R., Hall, J.M., Jaeger, C.C., Lowe, I., McCarthy, J.J., Schellnhuber, H.J., Bolin, B., Dickson, N.M., Faucheux, S., Gallopin, G.C., Grübler, A., Huntley, B., Jäger, J., Jodha, N.S., Kasperson, R.E., Mabogunje, A., Matson, P., Mooney, H., Moore III, B., O'Riordan, T. \& Svedin, U. (2001) Sustainability science. Science 292(5517): 641-2.

Kauffman, J. (2009) Advancing sustainability science: report on the International Conference on Sustainability Science (ICSS) 2009. Sustainability Science 4(2): 233-42.

Kemp, R., Parto, S. \& Gibson, R.B. (2005) Governance for sustainable development: moving from theory to practice. International Fournal of Sustainable Development 8(1): 12-30.

Klein, J.T. (2008) Evaluation of interdisciplinary and transdisciplinary research. American fournal of Preventive Medicine 35(2): 116-24.

Komiyama, H. \& Takeuchi, K. (2006) Sustainability science: building a new discipline. Sustainability Science 1(1): 1-6.

Kuhn, T.S. (1962) The Structure of Scientific Revolutions. Chicago, IL, USA: University of Chicago Press.

MA (2005) Ecosystems and Human Well-being: Synthesis. Washington, DC, USA: Island Press.

Martens, P. (2006) Sustainability: science or fiction? Sustainability: Science, Practice, E Policy 2(1): 36-41.

Martinez-Alier, J. (1987) Ecological Economics. London, UK: Basil Blackwell.

Meppem, T. \& Bourke, S. (1999) Different ways of knowing: a communicative turn to sustainability. Ecological Economics 30(3): $389-404$. 
Mittelstrass, J. (1992) Auf dem Wege zur Transdisziplinarität. GAIA 1(1): 250-7.

Moran, D.D., Wackernagel, M., Kitzes, J.A., Goldfinger, S.H. \& Boutaud, A. (2008) Measuring sustainable development nation by nation. Ecological Economics 64(3): 470-4.

Morus, T. (1517) Utopia. De optimo rei publicae statu. Basel, Switzerland.

Nowotny, H., Scott, P. \& Gibbons, M. (2001) Re-thinking science: knowledge and the public in an age of uncertainty. Cambridge, $\mathrm{UK}$ : Polity Press.

O’Connor, M. \& Arnoux, R. (1992) Ecologie, échange inéluctable, et éthique de l'engagement (sur le don et le développement durable). Revue du MAUSS 15-16: 288-309.

Ostrom, E., Janssen, M.A. \& Anderies, J.M. (2007) Going beyond panaceas. Proceedings of the National Academy of Sciences USA 104(39): 15176-8.

Rapport, D.J. (2007) Sustainability science: an ecohealth perspective. Sustainability Science 2(1): 77-84.

Raskin, P.D. (2008) World lines: a framework for exploring global pathways. Ecological Economics 65(3): 461-70.

Raskin, P., Banuri, Z., Gallopin, G., Hammond, A., Kates, R. \& Swart, R. (2002) Great Transition. The promise and Lure of the Times Ahead. Boston, CT, USA: Stockholm Environmental Institute.

Reisch, L.A. \& Røpke, I., eds (2004) Sustainable Consumption and Ecological Economics. Aldershot, UK: Edward Elgar Publishing.

Rotmans, J., Kemp, R. \& van Asselt, M. (2001) More evolution than revolution: transition management in public policy. Foresight $3(1)$ : $15-31$.

Settele, J., Kühn, I., Klotz, I., Hammen, V. \& Spangenberg, J.H. (2007) Is the EC afraid of its own visions? Science 315: 1220.

Settele, J., Spangenberg, J.H., Hammen, V., Harpke, A., Klotz, S., Rattei, S., Schmidt, A., Schweiger, O., Stoll-Kleemann, S., Zaunberger, K. \& Kühn, I. (2010a) Integration in largescale research: on the art and science of coordination. In: Atlas of Biodiversity Risk, ed. J. Settele, L. Penev, T. Georgiev, R. Grabaum, V. Grobelnik, V. Hammen, S. Klotz, M. Kotarac \& I. Kühn, pp. 229-230. Sofia, Bulgaria and Moscow, Russia: Pensoft Publishing.

Settele, J., Spangenberg, J.H. \& Kühn, I. (2008) Large projects can create useful partnerships. Nature 453: 850.

Settele, J., Zobel, M., Spangenberg, J.H., Klotz, S., Hammen, V. \& Kühn, I. (2010b) Designing projects for integrated research - the ALARM experience. In: Atlas of Biodiversity Risk, ed. J. Settele, L. Penev, T. Georgiev, R. Grabaum, V. Grobelnik, V. Hammen, S. Klotz, M. Kotarac \& I. Kühn, pp. 208-209. Sofia, Bulgaria and Moscow, Russia: Pensoft Publishing.

Söderbaum, P. (2000) Ecological Economics. London, UK: Earthscan. Spangenberg, J.H. (2003) Forschung für Nachhaltigkeit. Herausforderungen, Hemmnisse, Perspektiven. In: Handbuch nachhaltige Entwicklung. Wie ist nachhaltiges Wirtschaften machbar?, ed. G. Linne \& M. Schwarz, pp. 531-550. Opladen, Germany: Leske \& Buderich.
Spangenberg, J.H. (2006) Sustainable development in a globalising world. Dealing with complexity. European approaches and experiences: a survey [www document]. URL http://seri.ac ademia.edu/JoachimHSpangenberg/Talks/40868/Sustainable_ Development_in_a_Globalising_World_Dealing_with_Complex ity_European_Approaches_and_Experiences_A_Survey

Spangenberg, J.H. (2007) The institutional dimension of sustainable development. In: Sustainable Indicators: A Scientific Assessment, ed. T. Hak, B. Moldan \& A.L. Dahl, pp. 107-26. Washington, DC, USA and London, UK: Island Press.

Spangenberg, J.H. (2008) Sustainability strategies. History, concepts, relevance. In: Sustainable Development. Past Conflicts and Future Challenges. Taking Stock of the Sustainability Discourse, ed. J.H. Spangenberg, pp. 7-19. Münster, Germany: Westfälisches Dampfboot.

Spangenberg, J.H. (2010) World civilisations at crossroads: towards an expansionist or a sustainable future. Lessons from history. Futures 42(6): 565-73.

Spangenberg, J.H. \& O'Connor, M. (2010) Sustainability science: a new mode of science, another step in the evolution of science paradigms. Global Responsibility 61: 13-16.

Spangenberg, J.H. \& Settele, J. (2010) Precisely incorrect? Monetising the value of ecosystem services. Ecological Complexity 7(3): 327-37.

Stieglitz, J.E., Sen, A. \& Fitoussi, J.-P. eds (2009) Report by the Commission on the Measurement of Economic Performance and Social Progress [www document]. URL http://www.stiglitz-senfitoussi.fr

UNEP (2007) GEO 4 Global Environment Outlook. Environment for Development. Valletta, Malta: Progress Press.

van den Hove, S. (2007) A rationale for science-policy interfaces. Futures 39(7): 807-26.

van der Sluijs, J., ed. (2002) Management of Uncertainty in Science for Sustainability. Utrecht, the Netherlands: Copernicus Institute, Utrecht University.

Wallerstein, I. (1974). The Modern World-System. New York, NY, USA: Academic Press

WCED (1987) Our Common Future. Oxford, UK: Oxford University Press.

Weaver, P.M. \& Rotmans, J. (2006) Integrated sustainability assessment: what is it, why do it and how? International fournal of Innovation and Sustainable Development 1(4): 284-303.

Weinstein, M.P. (2010) Sustainability science: the emerging paradigm and the ecology of cities. Sustainability: Science, Practice, \& Policy 6(1): 1-5.

Yarime, M., Takeda, Y. \& Kajikawa, Y. (2010) Towards institutional analysis of sustainability science: a quantitative examination of the patterns of research collaboration. Sustainability Science 5(1): 11525.

Zuindeau, B. (2007) Régulation school and environment: theoretical proposals and avenues of research. Ecological Economics 62(2): 281-90. 